\title{
An Analysis of Hofstede's 5 Cultural Dimensions Functioning in Ren Zhengfei's Intercultural Communication With BBC Reporter
}

\author{
Qinpei Fan \\ No. 100 Shuifeng Road, Shanghai Publishing and Printing College, Shanghai, China \\ *Corresponding author.Email: 39312543@qq.com
}

\begin{abstract}
In the context of economic globalization, communication and coordination are the best way to seek long-term development. Ren Zhengfei's interview with a BBS reporter conveyed the message that Huawei is actively communicating with the West. This article intends to analyze the 5 cultural dimensions in this cross-cultural communication: Individualism/Collectivism; Long-term/Short term orientation; Uncertainty Avoidance; Masculinity/Femininity; Power distance. Ren Zhengfei's good grasp of cross-cultural communication skills is based on his understanding of the differences between Chinese and British cultures in different cultural dimensions, which ensured the harmonious communication and as a result guarantee a positive development of Huawei's relationship with Britain, as well as with Western cultures.
\end{abstract}

Keywords: Individualism/Collectivism, Long-term/Short term orientation, Uncertainty avoidance, Masculinity/Femininity, Power distance.

On Dec. 1st, 2018, Huawei CFO Meng Wanzhou was arrested in Vancouver, Canada. Objectively, with the development and changes of the economy and the market, China will inevitably enter a new stage of development. In this process of transformation and upgrading, Huawei is a pioneer. In the Sino-US trade friction, Huawei has received frontal blow. However, China and the US market, China and the European market, China and the global market have long been closely linked. Communication and coordination are the best way to seek long-term development.

\section{INTRODUCTION}

On February 18, 2019, Ren Zhengfei accepted an exclusive interview with the BBC. Through this interview, he conveyed a positive message of hope to communicate with the West. The BBC reporter asked very sharply. Ren Zhengfei answered all the questions that the reporters (or the Western society) were concerned about. The founding and development of Huawei are closely related to China's reform, opening-up, and development. Ren Zhengfei's answers to objective facts vividly reveal that period of Chinese history, reflecting Chinese culture and Chinese values, while his subjective analysis is in view of British culture. Ren Zhengfei's good grasp of cross-cultural communication skills is based on his understanding of the differences between Chinese and British cultures in different cultural dimensions (Individualism/Collectivism; Long-term/Short term orientation; Uncertainty Avoidance; Masculinity/Femininity; Power distance), which ensured the harmonious communication and as a result guarantee a positive development of Huawei's relationship with Britain, as well as with Western cultures.

\section{HOFSTEDE'S FIVE CULTURAL DIMENSIONS}

Geert Hofstede's studies of cultural differences in value orientation offer an illuminating approach to understanding the range of cultural differences. Through theoretical reasoning and statistical analysis, Hofstede identify five dimensions along which dominant patterns of a culture can be ordered: Individualism versus collectivism, uncertainty avoidance, power distance, masculinity versus femininity, and long-term versus short-term orientation to time. The smooth 
communication of this interview should give credit to Ren Zhengfei's good grasp of the differences of cultural values and social behaviors between China and Britain in those five dimensions.

\subsection{Individualism versus Collectivism}

Cultures vary in their tendency to encourage people to be unique and independent or conforming and interdependent. Hofstede refers to these variations as the individualism-collectivism dimension, the degree to which a culture relies on and has an allegiance to the self or the group. $\mathrm{He}$ created an individualism-collectivism index (IDV)[1] to assess a culture's relative location on the individualism-collectivism dimension. Such cultures as USA (91), Australia (90), Great Britain (89) have relatively high IDVs and therefore are highly individualistic, believe that people are only supposed to take care of themselves, and perhaps their immediate families. Such cultures as China (20), South Korea (18), and Pakistan (14) all have relatively low IDVs and prefer a collectivist orientation as a cultural value. These cultures require an absolute loyalty to the group.

\section{Question 29 in the interview [2]:}

Journalist: "Now China is also saying that releasing your daughter could be a factor to consider in a trade war between China and the United States. It seems that your family has been involved in the trade negotiations between the two countries. How do you feel about that?"

Ren Zhengfei: "I don't know if the Chinese government has made this speech, I only know that Trump made this speech. In my opinion, the Meng Wanzhou incident has not caused trade negotiations between China and the United States from beginning to end. I have not seen a word in all news announcements. I only saw Trump's speech as a condition. The United States used it as a condition. I don't want us to affect the process of China's opening up and reform. I hope that our country will be open to the United States, to the United Kingdom, to the world, so that we can build this world through common development.

In collectivist cultures, decisions are always based on what is best for the group, and the groups to which a person belongs are the most important social units. In turn, the group is expected to look out for and take care of its individual members. Consequently, collectivist cultures believe in obligations to the group, dependence of the individual on organizations and institutions, a "we" consciousness, and an emphasis on belonging.

Ren zhengfei does not want Huawei, as an individual enterprise, to influence national decisions. In a collectivist culture, national interests were paramount. Ren shows the positive side of collectivism to the full: the interests of individuals are subordinated to and should serve the interests of the state, and only when the big family is good, can the small family be good. Similarly, China's reform and opening-up drive is also aimed at building a better world with people around the world.

\subsection{Long-term versus Short-term Orientation}

Cultures that promote a long-term orientation toward life value social order and long-range goals, and admire persistence, thriftiness, humility, a sense of shame, and status differences within interpersonal relationships. Such cultures as China (118), Japan (80), and Brazil (65) are relatively long-term oriented [3]

Cultures with a short-term orientation toward changing events have a deep appreciation for tradition, personal steadiness and stability, and an expectation of quick results following one's actions and immediate gratification of one's needs. Such cultures as Great Britain (25), U.S.A (29), and Germany (31) are relatively short-term oriented [4]

Question 3 in the interview [5]:

Journalist: "You have just described that Huawei experienced huge challenges and difficulties at the beginning of its establishment. But today, I know that Huawei has become a top player in the global telecom market. How did it do that?"

Ren Zhengfei: "I knew we didn't have that much force, so I narrowed it down to a little bit, and I started to attack inside, and a little bit of attack started to have some success, some accumulation, and we felt that this pinprick pressure principle worked, so we focused on this. In the past 30 years, we have organized from hundreds of people, thousands of people, tens of thousands of people to 180,000 people to focus on the information transmission field and invested 15 to 20 billion dollars every year. In terms of investment in scientific research, we are among the top five in the world."

Ren Zhengfei shared the secret of success of long-term investment in this way: Huawei puts fertilizer in the land, and the land becomes fertile. In the end, the land is still owned by Huawei and therefore Huawei doesn't take away the fertilizer. Without a public listing, Huawei would not worry about fluctuations in its financial statements. Huawei is pursuing long-term interests. But the listed company pays attention to its short-term profit, especially the financial statements. They can't invest too much, because if the profit is less, the stock falls down.

\subsection{Uncertainty Avoidance}

Hofstede has created an uncertainty avoidance index (UAI) [6] to assess a culture's relative location along the 
uncertainty avoidance dimension. Such cultures as Greece (112), Portugal (120), and Uruguay (100) have relatively high UAI and prefer to avoid uncertainty as a cultural value. While such cultures as Singapore (8), Jamaica (13) and Denmark (23) have relatively low UAI and therefore have a high tolerance for uncertainty and ambiguity. The UAI for China (40) and Great Britain (35) comes quite close. Those two countries share similar attitude towards uncertainty and ambiguity. Therefore they share mutual understanding in overcoming uncertainty.

\section{Question 15 in the interview:}

Journalist:" Are you saying that if some countries continue to raise security concerns about Huawei, Huawei will choose not to do business with them?"

Ren Zhengfei: "There are worries about us in the $U K$, which does not affect our investment in the UK. We recently bought 500 acres of land in Cambridge to build a light chip factory. We are the world leader in light chips. We are building factories to export to many countries in the future. Our British factory can accept the monitoring of the UK. The chips monitored by the UK can be sold to western countries. Why not? It's no longer made in China."

If some countries constantly raise concerns about Huawei's security, Huawei can avoid that market, but this does not mean that it will affect Huawei's reasonable strategic layout to reasonably avoid future uncertainties.

\subsection{Power Distance}

Hofstede has created a power distance index (PDI) to assess a culture's relative location on the power distance dimension [7]. Such cultures as Malaysia (104), Panama (95) and China (80) have relatively high PDIs and prefer large power distances. They believe that each person has a rightful and protected place in the social order, that the actions of authorities should not be challenged or questioned, that hierarchy and inequality are appropriate and beneficial. While such cultures as Austria (11), New Zealand (22) and Great Britain (35) have relatively low PDIs and prefer small power distance as a cultural value. They believe in the importance of minimizing social or class inequalities, questioning or challenging authority figures, reducing hierarchical organizational structures, and using power only for legitimate purposes.

Question 31 in the interview [8]:

Journalist:" How does it feel as a father to see your daughter facing such a difficult situation?"

Ren Zhengfei:" This matter has already happened, so feel at ease. Let's take the legal path to solve this problem. Meng Wanzhou worked very hard in her studies... She does a good job of finance. People who are doing well in finance are concerned about balance, management, and efficiency... I have three children. In fact, I pay attention to them, but each of them has his/her own personality. We can not always live in harmony."

The role of the father in a typical high-power dimensional culture should be the decision-maker and commander in the family. However, Ren Zhengfei is very democratic. The power distance between him and the three children is relatively small. He cherishes Meng Wanzhou's advantages and respects his children's personality development. This family culture is closer to the power distance dimension of the British family. It can also make the British feel the love and expectation of a father for his daughter. Ren Zhengfei repeatedly emphasized: " The US should release the evidence bit by bit to the public in the future." Although the United States is powerful, people in a low power distance culture believe that power should only be used for legitimate purposes.

\subsection{Masculinity versus Femininity}

Hofstede has created a masculinity index (MAS) [9] to assess a culture's relative location along the masculinity-femininity dimension. Such cultures as Japan(95), Hungary(88), Austria(79) have a relatively high MAS, and believe in achievement and ambition in judging people on the basis of their performance and in the right to display the material goods that have been acquired. While such cultures as $\operatorname{Sweden}(5), \operatorname{Norway}(8)$, Netherlands(14) have a relatively low MAS, and believe less in external achievements and shows of manliness and more in the importance of life choices that improve intrinsic aspects of the quality of life, such as service to others and sympathy for the unfortunate.

China (66) and Great Britain (66) are the same in the level of masculinity-femininity dimension. Both are on the relative high side.

\section{Question 28 in the interview [10]:}

Journalist:" With regard to your daughter, we understand that from your personal point of view, this is a difficult time. Your daughter is being held in Canada and is facing extradition requests from the United States. How do you feel about that? What would you do if your daughter is actually put in prison?"

Ren Zhengfei:" First of all, I object to this move by the United States, which is politically motivated and undesirable. I oppose it if there is a problem in a country sanctioned by the United States the United States adopts the method of arrest. But now that we have reached this point, we still turn to the courts to solve this problem...Great people in history have suffered hardships. Tribulation is also an important wealth of life." 
The image of his daughter in his mind is: "hardworking and knows how to get along with people" "very economical" "doing well in finance" "Even in the state of house arrest, she studied 8 courses online every day. She did not have her will to decline." "Tribulation is also an important wealth of life." Among all these comments, he emphasized and praised his daughter: hardworking, economical, iron-will (all are qualities necessary to success).

Meng Wanzhou was arrested for political reasons. Ren Zhengfei naturally felt distressed. His solution was to follow legal procedures in action, and psychologically give his daughter warm support and encouragement. Obviously, He has high expectations for Meng Wanzhou, hoping that she would remain fighting despite setbacks. He has devoted all his heart and soul to Huawei and is full of hope and confidence that Huawei will achieve higher achievements. He has a strong desire for success which is absolutely positive and understandable for the British People.

\section{CONCLUSION}

In the whole process of this intercultural communication, his analysis takes British culture and Western culture as the foothold, reflecting his respect for British culture and Western culture. The more people differ the more they have to learn from each other. When communicating interculturally, we should not only express our own views and pass on our own values, but also understand the other party's culture and values and think from the other party's perspective and respect the other party's culture and values. To do so, there are mutual respect and curiosity to overcome the frustrations caused by misunderstandings between different cultures.

\section{LITERATURE REFERENCES}

[1] http://clearlycultural.com/geert-hofstede-cultural-di mensions/individualism/

[2] https://www.sohu.com/a/302471173_386694

[3] http://clearlycultural.com/geert-hofstede-cultural-di mensions/individualism/

[4] http://clearlycultural.com/geert-hofstede-cultural-di mensions/individualism/

[5] https://www.sohu.com/a/302471173_386694

[6] http://clearlycultural.com/geert-hofstede-cultural-di mensions/individualism/

[7] http://clearlycultural.com/geert-hofstede-cultural-di mensions/individualism/

[8] https://www.sohu.com/a/302471173_386694

[9] http://clearlycultural.com/geert-hofstede-cultural-di mensions/individualism/

[10] https://www.sohu.com/a/302471173_386694

[11] Geert Hofstede, Cultures and Organizations: Software of the Mind, London: McGraw-Hill, 1991

[12] https://www.sohu.com/a/302471173_386694

[13] http://clearlycultural.com/geert-hofstede-cultural-di mensions 